\title{
Erratum to: The metaphysics of goodness in the ethics of Aristotle
}

\author{
Samuel Baker ${ }^{1}$
}

Published online: 5 June 2017

(C) Springer Science+Business Media Dordrecht 2017

\section{Erratum to: Philos Stud (2017) 174:1839-1856 DOI 10.1007/s11098-016-0824-y}

In the original publication of the article under the section, "Absolute goodness and the good as end" the sentence in the fourth paragraph that reads as: "To the extent...in the universe." should read as: "To the extent that goods are found in the universe, ends are found in the universe."

The sentence in the fifth paragraph under the same section that reads as: "If goods are...good of the doctor." should read as: "If goods are merely relative, then one speaks properly when one speaks of both 'the good of the thief' and 'the good of the doctor.'"

Finally, in the seventh paragraph under the section "Judging one substance to be (absolutely) better than another" the parenthesis that reads as: "(Meta. K 7, 1064b5-6; cf. Rhetoric I 7, 1364b7-8, my emphasis; cf. Meta. K 7, 1064b5-6)." should read as: "(Meta. K 7, 1064b5-6; cf. Rhetoric I 7, 1364b7-8)."

The online version of the original article can be found under doi:10.1007/s11098-016-0824-y.

Samuel Baker

samuelbaker@southalabama.edu

1 Philosophy Department, University of South Alabama, Mobile, AL, USA 